\title{
Trocas gasosas de variedades de fava sob condições de salinidade da água de irrigação
}

\section{Gas exchange of fava bean varieties under salinity conditions of irrigation water}

\author{
Márcio Henrique da Costa Freire \\ Universidade Federal do Ceará \\ E-mail: marciohcfreire@gmail.com \\ OrcID: https://orcid.org/0000-0002-5490-4115
}

Geocleber Gomes de Sousa

Universidade da Integração Internacional da Lusofonia Afro-Brasileira

E-mail: sousagg@unilab.edu.br

OrcID: https://orcid.org/0000-0002-1466-6458

Emanuel D'Araújo Ribeiro de Ceita

Universidade Estadual Paulista

E-mail: emanueldeceita@gmail.com

OrcID: https://orcid.org/0000-0002-9543-1094

Andreza Silva Barbosa

Universidade da Integração Internacional da Lusofonia Afro-Brasileira

E-mail: andrezabarbosaunilab@gmail.com OrclD: https://orcid.org/0000-0002-3136-497X

Geovana Ferreira Goes

Universidade da Integração Internacional da Lusofonia Afro-Brasileira

E-mail: ggoes64@gmail.com

OrclD: https://orcid.org/0000-0002-1699-1537

Claudivan Feitosa de Lacerda Universidade Federal do Ceará

E-mail: cfeitosa@ufc.br

OrcID: https://orcid.org/0000-0002-5324-8195

Resumo: O objetivo do presente estudo foi investigar os acessos de feijão-fava mais e menos tolerantes ao estresse salino em função das trocas gasosas foliares. O experimento foi conduzido em ambiente protegido em um delineamento experimental inteiramente casualizado (DIC), em esquema fatorial $5 \times 4$, referentes a cinco condutividades elétricas da água de irrigação - CEa: 1,0;2,0; 3,0; 4,0 e 5,0 dS m-1, e quatro variedades de fava (Branquinha - C1, Manteiguinha - C2, Espírito Santo - C3 e Orelha-de-vó - C4), com quatro repetições. Aos 35 dias após a semeadura (fase vegetativa) coletaram-se dados da condutância estomática (gs), fotossíntese $(A)$, transpiração $(E)$, eficiência instantânea do uso da água (A/E), concentração intercelular do $\mathrm{CO}_{2}(\mathrm{Ci})$ e temperatura foliar $(\mathrm{TI})$. Os sais afetaram negativamente as trocas gasosas das variedades de fava. Os graus de redução na taxa de fotossíntese indicam as variedades $C 1$ e $C 3$, respectivamente, com maior e menor capacidade tolerar o estresse salino.

Palavras-chave: Estresse salino. Fotossíntese. Material genético. Phaselous lunatus L. Transpiração.

Abstract: The objective of the present study was to investigate the access of more and less tolerant to saline stress due to leaf gas exchange. The experiment was conducted in a protected environment in completely randomized design (DIC), in a $5 \times 4$ factorial scheme, referring to the five electrical conductivity of irrigation

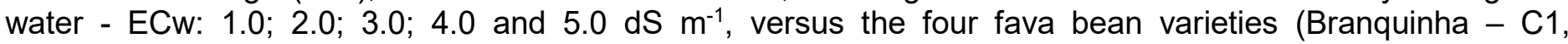
Manteiguinha - C2, Espírito Santo - C3 e Orelha-de-vó - C4), with four repetitions. At 35 days after sowing (vegetative phase), data on stomatal conductance $(g s)$, photosynthesis $(A)$, transpiration $(E)$, instant water use 
efficiency $(A / E)$, intercellular $\mathrm{CO}_{2}$ concentration $(\mathrm{Ci})$ and leaf temperature $(\mathrm{TI})$ were collected. The salts negatively affected the gas exchange of the broad bean varieties. The degrees of reduction in the rate of photosynthesis indicate varieties Branquinha and Espírito Santo, respectively, with greater and lesser capacity to tolerate salt stress.

Keywords: Genetic material. Phaselous lunatus L. Photosynthesis. Saline stress. Transpiration.

Data de recebimento: $17 / 05 / 2020$

Data de aprovação: $24 / 08 / 2020$

DOI: https://doi.org/10.30612/agrarian.v14i51.11958

\section{Introdução}

A produção mundial de alimentos enfrenta uma série de obstáculos que, por vezes, acabam inviabilizando o cultivo de espécies vegetais bases da alimentação humana, sendo a salinidade do solo e da água um dos principais problemas que acometem o sistema de produção das culturas em todo o mundo (Silva et al., 2013).

A salinidade é um dos estresses ambientais que afetam negativamente o crescimento e o metabolismo vegetal, além de ser um dos fatores responsáveis pelo decréscimo da produtividade de culturas nas regiões áridas e semiáridas (Barbosa et al., 2012). Segundo Amorim et al. (2010), o excesso de sais pode perturbar as funções fisiológicas e bioquímicas das plantas e afetar negativamente o metabolismo de carbono primário da maior parte das culturas devido aos efeitos osmóticos, hídricos e tóxicos de íons (Sousa et al., 2010).

Nas regiões semiáridas é muito comum a ocorrência de águas com alto teor de sais que, muitas vezes, acaba sendo o único recurso hídrico disponível para os produtores, devendo serem adotadas estratégias que visem contornar este problema (Neves et al., 2015). Dentre elas, destaca-se a utilização de materiais genéticos mais tolerantes, uma vez que a resposta de plantas submetidas ao estresse salino, conforme exposto por Ayers e Westcot (1999), pode variar tanto entre espécies como entre genótipos de uma mesma espécie e, identificar um genótipo cujos processos fisiológicos são menos afetados pelo estresse salino pode assegurar resultados satisfatórios, ainda que reduzidos (Granja et al., 2019; Pereira Filho et al., 2019).

A princípio, o estresse salino provoca efeitos de ordem osmótica resultando na restrição do transporte de água e, consequente, redução da abertura estomática que, a depender da espécie e da capacidade do genótipo de cada espécie em compartimentalizar íons salinos no interior do vacúolo, do balanço de íons $\mathrm{K}^{+} / \mathrm{Na}^{+}$e da síntese de solutos orgânicos, pode afetar diretamente as trocas gasosas das culturas (Taiz et al., 2017; Pereira Filho et al., 2019).

O feijão-fava (Phaseolus lunatus L.) é uma espécie caracterizada por possuir elevado potencial de produção e diversidade genética, se adaptando às mais diferentes condições ambientais, sendo considerada uma espécie mais tolerante à seca que o feijão comum (Barreiro Neto et al., 2015). Apesar de ser uma cultura bastante cultivada no semiárido brasileiro, são escassos os estudos sobre a resposta fisiológica no tocante as trocas gasosas em função de sua variabilidade genética e salinidade.

Em virtude disso, o objetivo do presente estudo foi investigar o acesso de feijão-fava mais tolerante e o menos tolerante ao estresse salino em função das trocas gasosas foliares.

\section{Material e Métodos}

O experimento foi conduzido em ambiente protegido durante os meses de março e abril de 2018 na Unidade de Produção de Mudas Auroras (UPMA) da Universidade da Integração Internacional da Lusofonia Afro-Brasileira (UNILAB), localizada no Campus das Auroras, pertencente ao município de Redenção, Ceará, na região do Maciço de Baturité, localizado nas coordenadas Latitude: $4^{\circ} 13^{\prime} 35^{\prime \prime}$ S, Longitude: $38^{\circ} 43^{\prime} 53^{\prime \prime} \mathrm{O}$, a $92 \mathrm{~m}$ de altitude. O clima da região é do tipo Aw', com temperatura média anual de $26{ }^{\circ} \mathrm{C}$ e a precipitação anual de $1086 \mathrm{~mm}$.

O ambiente protegido onde foi conduzido o experimento é do tipo arco de $8 \times 15 \mathrm{~m}$, coberto de plástico agrícola difusor 150 micra, com estrutura de aço galvanizado, laterais e frontais cobertas de telas sombrites a $50 \%$, pé direito de $3 \mathrm{~m}$, rodapé de alvenaria e o piso preenchido de brita tipo 3 . Durante a execução do 
experimento foram feitas as medidas de temperatura e umidade relativa com o aparelho digital "MAX-MIN THERMO HYGRO", cujo valores médios foram, respectivamente, $29,7^{\circ} \mathrm{C}$ e $60 \%$.

O solo utilizado foi um ARGISSOLO VERMELHO AMARELO (Santos et al., 2018) coletado na camada de 0 a $20 \mathrm{~cm}$ próximo da área experimental (Tabela 1), onde coletou-se uma amostra e, posteriormente, foi encaminhada para o laboratório para análise química, conforme as recomendações de Teixeira et al. (2017).

Tabela 1. Atributos físico-químicos do solo antes da aplicação dos tratamentos.

\begin{tabular}{|c|c|c|c|c|c|c|c|c|}
\hline \multicolumn{9}{|c|}{ Atributos } \\
\hline $\begin{array}{c}\text { Ds } \\
\left(\mathrm{g} \mathrm{cm}^{-3}\right)\end{array}$ & $\begin{array}{c}\mathrm{pH} \\
-\end{array}$ & $\begin{array}{c}\mathrm{MO} \\
\left(\mathrm{g} \mathrm{kg}^{-1}\right)\end{array}$ & $\mathrm{Ca}$ & $\mathrm{Mg}$ & $\begin{aligned} & \mathrm{Na} \\
&\left.=\mathrm{kg}^{-1}\right)\end{aligned}$ & $\mathrm{K}$ & $\begin{array}{c}V \\
(\%)\end{array}$ & $\begin{array}{c}\text { CEes } \\
\left(\mathrm{dS} \mathrm{m}^{-1}\right)\end{array}$ \\
\hline 1,4 & 6,1 & 10,06 & 0,8 & 1,8 & 0,17 & 2,09 & 80 & 2,25 \\
\hline
\end{tabular}

Ds - Densidade do solo; V - Saturação por base; CEes - Condutividade elétrica do extrato de saturação solo; MO - Matéria orgânica

Foram utilizadas quatro variedades de fava oriundas da região do Maciço de Baturité: Branquinha (C1), Manteiguinha (C2), Espírito Santo (C3) e Orelha-de-vó (C4). Foi utilizado delineamento experimental inteiramente casualizado (DIC), em esquema fatorial $5 \times 4$, referentes a cinco valores de condutividade elétrica da água de irrigação - CEa: 1,0; 2,0; 3,0;4,0 e 5,0 dS m $\mathrm{m}^{-1}$ e quatro variedades de fava com quatro repetições.

A semeadura foi realizada em março de 2018 em vasos plásticos com capacidade para $11 \mathrm{~L}$, contendo 5 sementes por vaso, numa profundidade de 2 centímetros. Aos 10 dias após a semeadura (DAS), fez-se o desbaste das plantas, deixando-se 2 plantas por vaso, dando início simultaneamente a aplicação dos tratamentos com água salina e aos 13 DAS realizou-se o tutoramento das plantas.

Durante o período de realização do experimento não foram necessárias práticas de controle de pragas e doenças, bem como não foram realizadas adubações de nenhuma natureza, realizando-se apenas capina manual de plantas espontâneas na superfície do solo.

$\mathrm{Na}$ preparação da água salina, foram utilizados os sais de $\mathrm{NaCl}, \mathrm{CaCl}_{2} \cdot 2 \mathrm{H}_{2} \mathrm{O}$ e $\mathrm{MgCl}_{2} \cdot 6 \mathrm{H}_{2} \mathrm{O}$, na proporção de 7:2:1, buscando-se simular a qualidade de águas salobras predominantes em parte do semiárido brasileiro (Medeiros, 1992). As águas foram preparadas em recipientes plásticos com capacidade para $60 \mathrm{~L}$, e a irrigação seguiu conforme a metodologia do lisímetro de drenagem (Bernardo et al., 2019) a partir dos 10 DAS até o final do experimento, deixando o solo à capacidade de campo e aplicando-se uma fração de lixiviação de 0,15 .

Para avaliar o efeito dos tratamentos, aos 35 DAS fez-se a medição dos dados das trocas gasosas foliares com o auxílio de um analisador de gás no infravermelho (LCi System, ADC, Hoddesdon, UK), em sistema aberto, com fluxo de ar de $300 \mathrm{~mL} \mathrm{~min}^{-1}$, em folhas completamente expandidas da região central de cada planta, sendo obtidas as seguintes variáveis: condutância estomática (gs), taxa de fotossíntese líquida $(A)$, transpiração $(E)$, eficiência instantânea do uso da água (A/E), concentração intercelular do $\mathrm{CO}_{2}(\mathrm{Ci})$ e temperatura foliar ( $\mathrm{TI})$. As leituras foram realizadas entre 10 e $11 \mathrm{~h}$, utilizando-se fonte de radiação artificial (cerca de $1.200 \mu \mathrm{mol} \mathrm{m} \mathrm{m}^{-2} \mathrm{~s}^{-1}$ ), e sob condições naturais de temperatura e concentração de $\mathrm{CO}_{2}$.

Os dados observados foram submetidos a análise de variância (ANOVA) pelo Software Assistat versão 7.7 Beta (Silva \& Azevedo, 2016). Os dados referentes aos níveis salinos foram submetidos à análise de regressão buscando-se ajustar equações com significados biológicos. $\mathrm{Na}$ análise de regressão, as equações de regressão que melhor se ajustaram aos dados foram escolhidas com base na significância dos coeficientes de regressão a $0,01\left(^{* *}\right)$ e $0,05\left(^{*}\right)$ de probabilidade pelo teste $F$ e no maior coeficiente de determinação $\left(R^{2}\right)$.

\section{Resultados e Discussão}

A interação condutividade elétrica da água (CEa) $x$ variedades de fava $(V)$ exerceu efeito significativo ( $p<0,01$ ou $p<0,05$ ) para as variáveis condutância estomática (gs), taxa de fotossíntese líquida $(A)$, transpiração $(E)$, eficiência do uso da água $(A / E)$, temperatura foliar (TI) e concentração intercelular de carbono (Ci) (Tabela 2). 
Tabela 2. Resumo da análise de variância para a condutância estomática (gs), fotossíntese (A), transpiração $(E)$, eficiência instantânea do uso da água (A/E), concentração interna de carbono (Ci) e temperatura da folha ( $\mathrm{TI})$ em plantas de fava irrigadas com águas salinas na fase vegetativa, aos 35 dias após a semeadura.

\begin{tabular}{|c|c|c|c|c|c|c|c|}
\hline \multirow{2}{*}{ FV } & \multirow{2}{*}{ GL } & \multicolumn{6}{|l|}{ QM } \\
\hline & & gs & A & $E$ & $A / E$ & $\mathrm{Ci}$ & $\mathrm{TI}$ \\
\hline CEa & 4 & $0,178^{* *}$ & $72,881^{* *}$ & $13,49^{\star *}$ & $1,713^{\star *}$ & $11905,143^{\star \star}$ & $8,631^{\star *}$ \\
\hline V & 3 & $0,007^{\mathrm{ns}}$ & $23,454^{* *}$ & $0,559^{\text {ns }}$ & $3,421^{* *}$ & $2655,489^{\star *}$ & $13,656^{\star *}$ \\
\hline CEa X V & 12 & $0,018^{* *}$ & $12,928^{* *}$ & $1,688^{* *}$ & $0,722^{* *}$ & $1015,692^{*}$ & $0,353^{* *}$ \\
\hline Tratamentos & 19 & $0,05^{\star \star}$ & $27,211^{\text {** }}$ & $3,994^{* *}$ & $1,357^{\star *}$ & $3567,123^{* *}$ & $4,196^{* *}$ \\
\hline Resíduo & 60 & 0,005 & 4,28 & 0,404 & 0,267 & 432,277 & 0,069 \\
\hline CV (\%) & - & 22,37 & 27,41 & 24,15 & 17,5 & 8,26 & 17 \\
\hline
\end{tabular}

FV - Fonte de variação; GL - Grau de liberdade; CV (\%) - Coeficiente de variação; (--) Os tratamentos são quantitativos. O Teste F não se aplica; $\left({ }^{*}\right)$ significativo ao nível de 0,01 de probabilidade $(p<0,01) ;\left({ }^{*}\right)$ significativo ao nível de 0,05 de probabilidade $(0,01=<p<$ $0,05)$; (ns) não significativo $(p>=0,05)$.

O estresse salino, normalmente, reduz a disponibilidade de água para as plantas pela redução do potencial osmótico no solo e pode, em consequência, afetar diretamente as trocas gasosas foliares das culturas por efeito de fitoxicidade de íons (Sousa et al., 2010).

A condutância estomática (gs) das variedades de fava foi reduzida com o aumento da condutividade elétrica da água de irrigação (Figura 1).

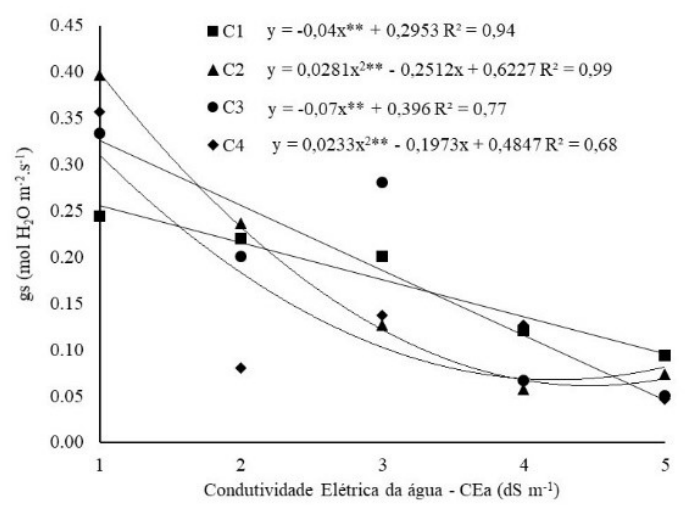

Figura 1. Condutância estomática das variedades de fava Branquinha (C1), Manteiguinha (C2), Espírito Santo (C3) e Orelha-de-vó (C4) irrigadas com águas salinas.

Ajustou-se um modelo polinomial quadrático para as variedades $\mathrm{C} 2$ e $\mathrm{C} 4$, obtendo-se valores de 0,06 e $0,07 \mathrm{~mol} \mathrm{H}_{2} \mathrm{O} \mathrm{m} \mathrm{m}^{-2} \mathrm{~s}^{-1}$ nas águas de 4,47 e 4,23 $\mathrm{dS} \mathrm{m}^{-1}$, respectivamente. Para as variedades $\mathrm{C} 1$ e $\mathrm{C} 3 \mathrm{o}$ modelo linear decrescente foi o que melhor se ajustou, obtendo-se numa água de $1,0 \mathrm{dS} \mathrm{m}^{-1} 0,24$ e $0,33 \mathrm{~mol}$ $\mathrm{H}_{2} \mathrm{O} \mathrm{m} \mathrm{m}^{-2} \mathrm{~s}^{-1}$, cujos valores foram reduzidos em 62,5\% $\left(0,09 \mathrm{~mol} \mathrm{H}_{2} \mathrm{O} \mathrm{m} \mathrm{m}^{-1}\right)$ e 84,8\%, $\left(0,05 \mathrm{~mol} \mathrm{H}_{2} \mathrm{O} \mathrm{m}^{-2} \mathrm{~s}^{-1}\right)$, respectivamente, na água de maior salinidade $\left(5,0 \mathrm{dS} \mathrm{m}^{-1}\right)$.

A salinidade é um dos estresses abióticos que mais causam distúrbios fisiológicos progressivos nas plantas, começando pela fase osmótica, na qual os sais presentes na solução do solo reduzem o potencial osmótico no solo e dificultam a absorção de água pelas raízes das plantas como resposta aclimatativa para que a planta evite a perda excessiva de água, comprometendo a abertura estomática (Praxedes et al., 2014).

Pereira Filho et al. (2019) avaliando os efeitos da salinidade da água de irrigação sobre as trocas gasosas da fava, verificaram que a salinidade reduziu de forma linear a condutância estomática da cultura com o aumento da CEa. De forma semelhante, Sousa et al. (2018a) avaliando o efeito da salinidade da água de irrigação nas trocas gasosas da cultura da soja, obtiveram resultados nos quais o aumento da salinidade da água de irrigação reduziu linearmente a condutância estomática das plantas de soja.

As variedades de fava C2 e C3 sofreram redução linear da taxa de fotossíntese líquida (A) com os crescentes níveis da condutividade elétrica da água de irrigação, alcançando níveis de 4,71 e 3,38 $\mu \mathrm{mol} \mathrm{CO}_{2}$ $\mathrm{m}^{-2} \mathrm{~s}^{-1}$, respectivamente, na água de maior $\mathrm{CEa}$, com a variedade C4 apresentando comportamento polinomial quadrático, alcançando uma taxa de fotossíntese de $4,64 \mu \mathrm{mol} \mathrm{CO}_{2} \mathrm{~m}^{-2} \mathrm{~s}^{-1}$ numa CEa de 4,78 dS $\mathrm{m}^{-1}$ (Figura 2). Já a variedade $\mathrm{C} 1$ apresentou comportamento polinomial quadrático atingindo em valores de 
2,06 dS m $\mathrm{m}^{-1}$ uma taxa de fotossíntese de $9,54 \mu \mathrm{mol} \mathrm{CO}_{2} \mathrm{~m}^{-2} \mathrm{~s}^{-1}$. Dentre todas as variedades utilizadas, a taxa de fotossíntese foi mais afetada no acesso C3, este apresentando redução de $64,0 \%$ para a água com maior CEa.

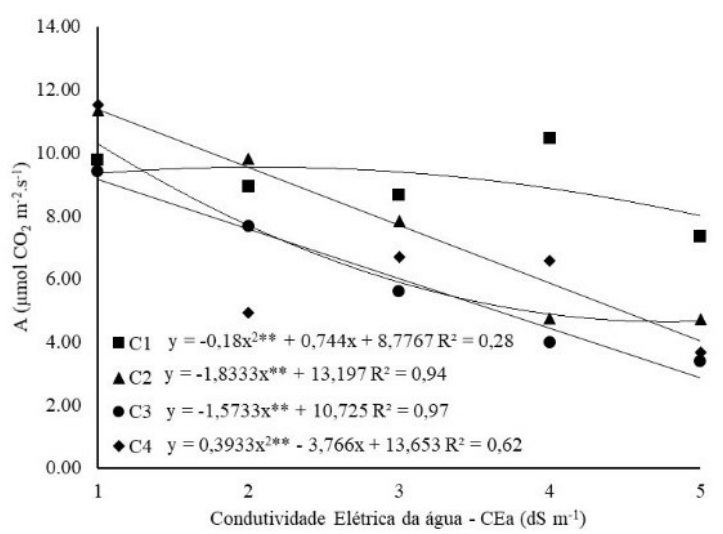

Figura 2. Taxa de fotossíntese líquida das variedades de fava Branquinha (C1), Manteiguinha (C2), Espírito Santo (C3) e Orelha-de-vó (C4) irrigadas com águas salinas.

O fechamento parcial dos estômatos, ocasionado pelos efeitos osmóticos da presença dos sais na solução do solo pode afetar o metabolismo das plantas causando-lhes alterações fisiológicas pela absorção de íons tóxicos como $\mathrm{Na}^{+}$e $\mathrm{Cl}^{-}$que acabam se acumulando nos cloroplastos das células e afetando diretamente a fotossíntese das plantas, reduzindo-a, embora haja o ajustamento osmótico (Taiz et al., 2017; Sá et al., 2015). A cultura da fava quando submetida ao estresse salino apresentou reduções na taxa de fotossíntese com o aumento da condutividade elétrica da água de irrigação (Pereira Filho et al., 2019). De forma similar, Prazeres et al. (2015) também constataram reduções na taxa de fotossíntese na cultura do feijão-caupi irrigada com água salina.

$\mathrm{Na}$ Figura 3 pode ser observado o comportamento das variedades quanto à transpiração $(E)$, mostrando que C2, C3 e C4 tiveram decréscimos lineares em sua transpiração com o aumento crescente da CEa até o nível de 5,0 dS $\mathrm{m}^{-1}$, sendo reduzida em 60,7, 66,3 e 71,2\%, alcançando valores de 1,79, 1,33 e

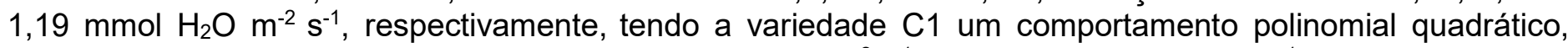
apresentando uma taxa transpiratória de $3,15 \mathrm{mmol} \mathrm{H}_{2} \mathrm{O} \mathrm{m}^{-2} \mathrm{~s}^{-1}$ numa CEa de 2,36 dS m $\mathrm{m}^{-1}$, sendo este último a apresentar melhores resultados para esta variável, com a C4 a mais afetada pela presença crescente dos sais na água de irrigação pelo maior decréscimo apresentado dentre os acessos.

Esse comportamento das variedades de redução da transpiração pode estar relacionado diretamente com a redução da condutância estomática e com a regulação da quantidade de água absorvida pelas raízes como estratégia em resposta à perda de água, uma vez que sua absorção é limitada pela redução do potencial osmótico da solução do solo (Prazeres et al., 2015).

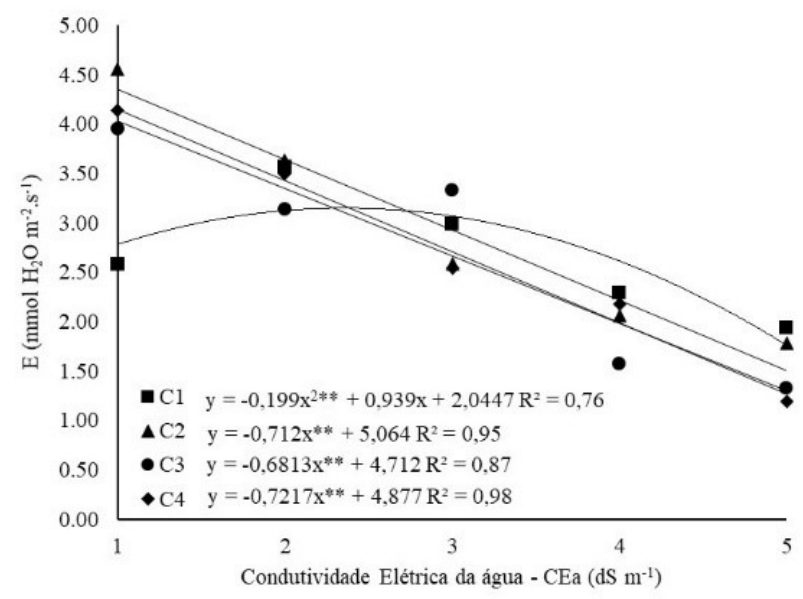

Figura 3. Transpiração das variedades de fava Branquinha (C1), Manteiguinha (C2), Espírito Santo (C3) e Orelha-de-vó (C4) irrigadas com águas salinas. 
Avaliando as trocas gasosas na cultura da fava, Sousa et al. (2018b) verificaram que a transpiração da fava também sofreu reduções quando irrigada com águas de níveis crescentes de condutividade elétrica. Em estudos similares a este, Sousa et al. (2018a) também verificaram redução na transpiração da cultura do feijão de corda com o aumento da concentração de sais na água de irrigação.

As variedades $\mathrm{C} 2$ e C4 apresentaram modelos polinomiais quadráticos quanto à eficiência instantânea do uso da água (A/E) (Figura 4). Para CEa's de 3,55 e 2,13 dS m $\mathrm{d}^{-1}$ as variedades obtiveram, respectivamente, eficiências de 3,21 e 2,63 $\mu \mathrm{mol} \mathrm{mmol} \mathrm{H}_{2} \mathrm{O} \mathrm{m} \mathrm{m}^{-2} \mathrm{~s}^{-1}$. Já a $\mathrm{C} 3$ demonstrou comportamento linear abaixo das demais variedades apresentando um incremento de 5,8\% na CEa mais elevada, no qual obteve valor de 2,55

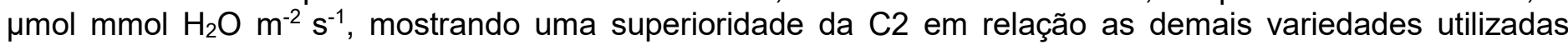
quanto à esta variável. Com relação a $\mathrm{C} 1$, obteve-se numa CEa de 2,41 $\mathrm{dS} \mathrm{m}^{-1}$ uma eficiência de $3,15 \mu \mathrm{mol}$ $\mathrm{mmol} \mathrm{H}_{2} \mathrm{O} \mathrm{m} \mathrm{m}^{-2}$.

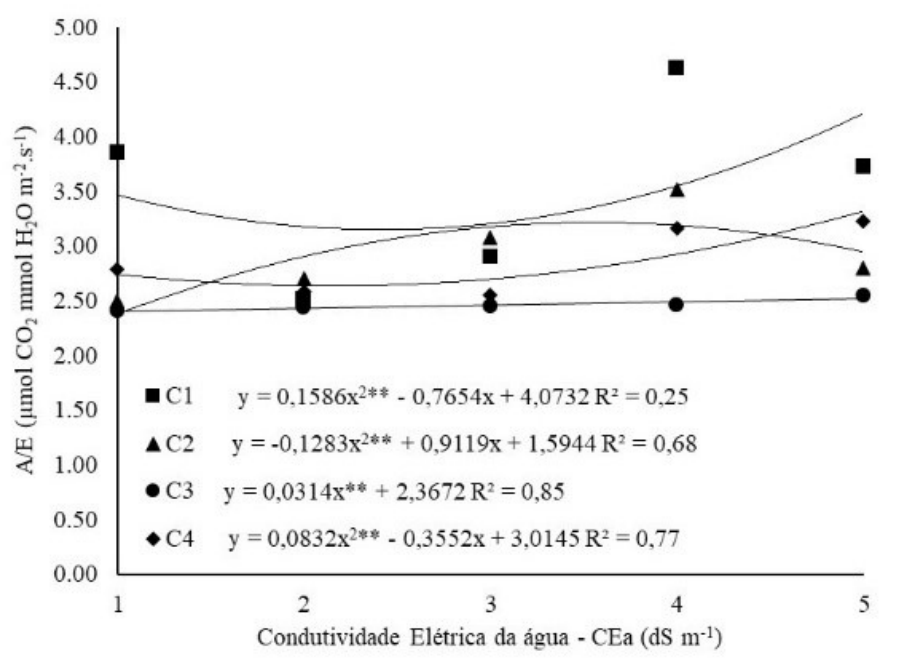

Figura 4. Eficiência instantânea do uso da água das variedades de fava Branquinha (C1), Manteiguinha (C2), Espírito Santo (C3) e Orelha-de-vó (C4) irrigadas com águas salinas.

Estudos desenvolvidos por Andrade et al. (2018) em diferentes genótipos de feijão caupi irrigados com água de baixa e alta salinidade revelaram que a eficiência do uso da água foi reduzida quando a irrigação foi

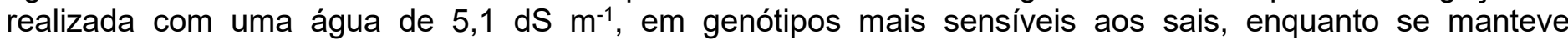
naqueles mais tolerantes, obtendo-se resultados semelhantes no presente estudo. De maneira contrária, Sousa (2017) avaliando os comportamentos vegetativo, fisiológico e produtivo na cultura do meloeiro sob salinidade, não verificou influência dos sais no comportamento da cultura quanto a eficiência do uso da água.

A eficiência instantânea no uso da água é expressa pela relação direta entre a fotossíntese e a transpiração, relacionando a quantidade de carbono que a planta fixa por cada unidade de água que perde. Em virtude disso, plantas capazes de aumentar a relação A/E quando expostas ao estresse salino possivelmente apresentem certa tolerância aos efeitos deste estresse pela exclusão de íons específicos pelas raízes graças a baixa absorção de água pelas mesmas ou pela produção de compostos orgânicos que auxiliam a regulação osmótica no interior da planta, Por outro lado, menor relação A/E sob estresse salino pode estar relacionada a problemas fisiológicos atuantes no fotossistema II pela redução do consumo de água proveniente da resistência estomática (Taiz et al., 2017).

A concentração interna de carbono (Ci), representada na Figura 5, sofreu reduções com o aumento da CEa, de forma que o modelo que melhor se ajustou para as variedades C1, C3 e C4 foi o linear decrescente, com resultados de 220, 242,67 e 209,67 ppm de carbono intercelular, que representam reduções de 19,5, 16,3 e $23,0 \%$. Os dados para C2 se ajustaram a um modelo polinomial quadrático, sendo que esta obteve $224,70 \mathrm{ppm}$ de $\mathrm{C}$ numa CEa de 4,41 dS $\mathrm{m}^{-1}$. Dentre as variedades trabalhados, a C3 apresentou maiores concentrações internas de carbono, demonstrando baixa eficiência em sua assimilação em relação as demais variedades trabalhadas, com menores concentrações observadas em C1. 


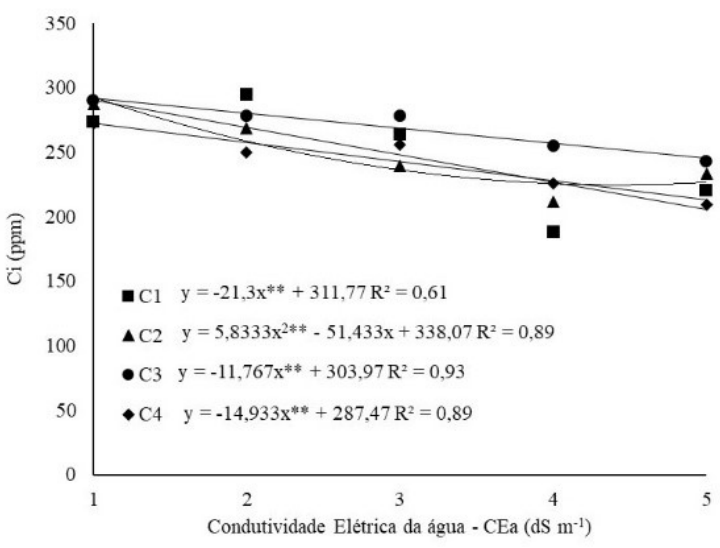

Figura 5. Concentração intercelular de carbono das variedades de fava Branquinha (C1), Manteiguinha (C2), Espírito Santo (C3) e Orelha-de-vó (C4) irrigadas com águas salinas.

A maior condutância dos estômatos favorece a entrada de $\mathrm{CO}_{2}$ nos tecidos foliares, aumentando sua concentração interna e, consequentemente, a fotossíntese (Taiz et al., 2017). Entretanto, com a redução da condutância estomática evidenciada no presente estudo, a tendência dos acessos é a de reduzir a quantidade de carbono nas células foliares, pelo aumento da resistência estomática, fazendo com que esta concentração seja inversamente proporcional à taxa de fotossíntese pela redução em sua assimilação, o que explicaria tal superioridade de acúmulo em C3 (Sá et al., 2018).

Souza et al. (2011) estudando o acúmulo de solutos orgânicos em feijão caupi submetido à salinidade, obtiveram menores taxas de assimilação de carbono, justificando-se pela redução da abertura dos estômatos, o que foi observado também no presente estudo. Por outro lado, Andrade et al. (2018) avaliando as trocas gasosas em genótipos de feijão-caupi irrigados com água salina, verificaram aumento das concentrações internas de $\mathrm{CO}_{2}$ atribuindo tais resultados à baixa atividade da enzima ribulose-1,5-bisfosfato carboxilaseoxigenase.

Quanto à temperatura da folha (TI), todas as variedades sofreram um aumento linear, (Figura 6). Os maiores valores de temperatura foliar foram obtidos pela $\mathrm{C} 4$ na água de $5,0 \mathrm{dS} \mathrm{m}^{-1}, \operatorname{com~} 36,3{ }^{\circ} \mathrm{C}$, tendo a variedade $\mathrm{C} 1$ um comportamento inverso, obtendo os menores valores de temperatura foliar para o mesmo nível salino $\left(34,5^{\circ} \mathrm{C}\right)$.

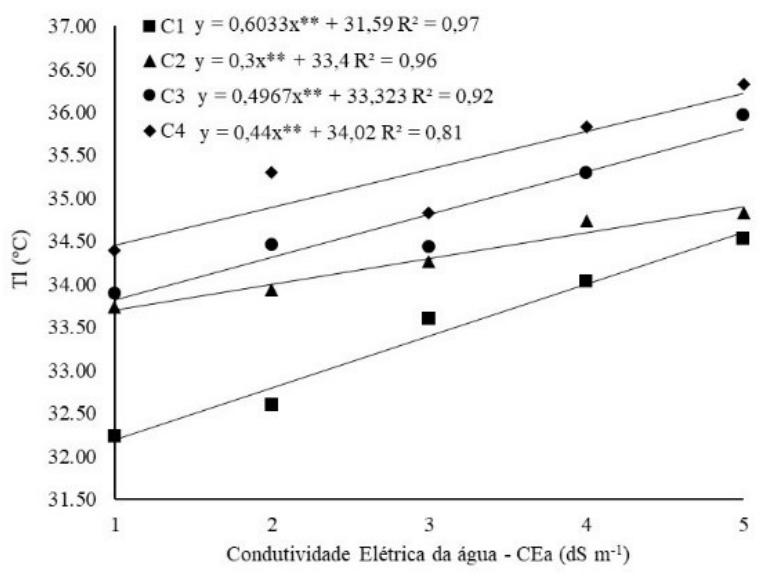

Figura 6. Temperatura foliar das variedades de fava Branquinha (C1), Manteiguinha (C2), Espírito Santo (C3) e Orelha-de-vó (C4) irrigadas com águas salinas.

Em trabalhos realizados por Sousa et al. (2012) avaliando as trocas gasosas e teores de macro e micronutrientes em folhas de pinhão manso cultivados sob condições de salinidade, foi possível verificar aumento linear da temperatura da folha com o aumento progressivo da condutividade elétrica da água de irrigação até uma CEa máxima de $3,0 \mathrm{dS} \mathrm{m}^{-1}$, obtendo valores de $32,03^{\circ} \mathrm{C}$. 
Esta tendência no aumento na temperatura foliar pode ser resultado direto da redução da transpiração na cultura da fava, uma vez que a transpiração é um dos mecanismos fisiológicos reguladores da temperatura interna da planta e esta, por ter sido reduzida como resultado da diminuição das aberturas estomáticas (Sousa et al., 2012), o que verificou-se neste trabalho, possuindo C1 menores valores de temperatura foliar em comparação com as demais variedades, que muito embora sua transpiração tenha atingido um pico, sofreu redução a partir da água de $3,0 \mathrm{dS} \cdot \mathrm{m}^{-1}$.

\section{Conclusões}

Os sais afetam negativamente as trocas gasosas foliares das variedades de fava. As variedades Branquinha e Espírito Santo, respectivamente, possuem a maior e menor capacidade de tolerar o estresse salino, seguido das variedades Orelha-de-vó e Manteiguinha com resultados menos satisfatórios.

\section{Referências}

Amorim, A.V., Gomes-Filho, E., Bezerra, M.A., Prisco, J.T., Lacerda, C.F. (2010). Respostas fisiológicas de plantas adultas de cajueiro anão precoce à salinidade. Revista Ciência Agronômica,.41(5), 113-121. https://doi.org/10.5935/1806-6690.20100016.

Andrade, J.R., Maia Júnior, S.O., Silva, R.F.B., Barbosa, J.W.S., Nascimento, R., Alencar, A.E.V. (2018). Trocas gasosas em genótipos de feijão-caupi irrigados com água salina. Revista Brasileira de Agricultura Irrigada, 12(3), 2653-2660. https://doi.org/10.7127/rbai.v12n300829.

Ayers, R.S., Westcot, D.W. (1999). A qualidade da água na agricultura. 2.ed. Campina Grande: UFPB.

Barbosa, F.S., Lacerda, C.F., Ghey, H.R., Farias, G.C., Silva Júnior, R.J.C., Lage, Y.A. (2012). Yield and ion content in maize irrigated with saline water in a continuous or alternating system. Ciência Rural, 42(10), 17311737. https://doi.org/10.1590/S0103-84782012001000003.

Barreiro Neto, M., Fagundes, R.A.A., Barbosa, M.M., Arriel, N.H.C., Franco, C.F.O., Santos, J.F. (2015). Características morfológicas e produtivas em acessos de feijão-fava consorciados. Tecnologia \& Ciência Agropecuária, 9(3), 23-27.

Bernardo, S., Mantovani, E.C., Silva, D.D., Soares, A.A. (2019). Manual de Irrigação. 9. ed. Viçosa: UFV.

Granja, M.B., Vitorino, P.J.P., Sousa, V.F.O., Rodrigues, M.H.B.S., Diniz, G.L., Andrade, F.H.A., Nobre, R.G. (2019). Variedades de feijão-fava submetidas a níveis de salinidade e adubação orgânica. Colloquium Agrariae, 15(1), 104-114. https://doi.org/10.5747/ca.2019.v15.n1.a275.

Medeiros, J.F. Qualidade da água de irrigação utilizada nas propriedades assistidas pelo "GAT" nos Estados do RN, PB, CE e avaliação da salinidade dos solos. (1992). Ano de obtenção: 1992. 173 f. Dissertação (Mestrado) - Universidade Federal da Paraíba.

Neves, A.L.R., Lacerda, C.F., Sousa, C.H.C., Silva, F.L.B, Gheyi, H.R., Ferreira, F.J., Andrade Filho, F.L. (2015). Growth and yield of cowpea/sunflower crop rotation under diferente irrigation management strategies with saline water. Ciência Rural, 45(5), 814-820. https://doi.org/10.1590/0103-8478cr20131657.

Pereira Filho, J.V., Viana, T.V.A., Sousa, G.G., Chagas, K.L., Azevedo, B.M., Pereira, C.C.M.S. (2019). Physiological responses of lima bean subjected to salt and water stresses. Revista Brasileira de Engenharia Agrícola e Ambiental, 23(12), 959-965. http://dx.doi.org/10.1590/1807-1929/agriambi.v23n12p959-965.

Praxedes, S.C., Damatta, F.M., Lacerda, C.F., Prisco, J.T., Gomes Filho, E. (2014). Salt stress tolerance in cowpea is poorly related to the ability to cope with oxidative stress. Acta Botanica Croatica, 73(1), 51-62. https://doi.org/10.2478/botcro-2013-0010.

Prazeres, S.S., Lacerda, C.F., Barbosa, F.E.L., Amorim, A.V., Araújo, I.C.S., Cavalcante, L.F. (2015). Crescimento e trocas gasosas de plantas de feijão-caupi sob irrigação salina e doses de potássio. Revista Agro@mbiente On-line, 9(2), 111-118. http://dx.doi.org/10.18227/1982-8470ragro.v9i2.2161.

Sá, F.V.S., Brito, M.E.B., Andrade Silva, L., Moreira, R.C.L., Fernandes, P.D., Figueiredo, L.C. (2015). Fisiologia da percepção do estresse salino em híbridos de tangerineira "Sunki Comum" sob solução hidropônica salinizada. Comunicata Scientiae, 6(4), 463-470. https://doi.org/10.14295/cs.v6i4.1121. 
Sá, F.V.S., Ferreira Neto, M., Lima, Y.M., Paiva, E.P., Prata, R.C., Lacerda, C.F., Brito, M.E.B. (2018). Growth, gas exchange and photochemical efficiency of the cowpea bean under salt stress and phosphorus fertilization. Comunicata Scientiae, 9(4), 668-679. https://doi.org/10.14295/cs.v9i4.2763.

Santos, H.G., Jacomine, P.K.T., Anjos, L.H.C., Oliveira, V.A., Lumbreras, J.F., Coelho, M.R., Almeida, J.A., Araujo Filho, J.C., Oliveira, J.B., Cunha, T.J.F. (2018). Sistema brasileiro de classificação de solos. 5.ed. Brasília: Embrapa Informação Tecnológica.

Silva, F.A.S., Azevedo, C.A.V. (2016). The Assistat Software Version 7.7 and its use in the analysis of experimental data. Africa Journal and Agriculture Researche, 11(39), 3733-3740. https://doi.org/10.5897/AJAR2016.11522.

Silva, F.L.B., Lacerda, C.F., Neves, A.L.R., Sousa, G.G., Sousa, C.H.C., Ferreira, F.J. (2013). Irrigação com águas salinas e uso de biofertilizante bovino nas trocas gasosas e produtividade de feijão-de-corda. Irriga, 18(4), 304-317. https://doi.org/10.15809/irriga.2013v18n2p304.

Sousa, A.E.C., Lacerda, C.F., Gheyi, H.R., Soares, F.A.L., Uyeda, C.A. (2012). Teores de nutrientes foliares e respostas fisiológicas em pinhão manso submetido a estresse salino e adubação fosfatada. Revista Caatinga, 25(2), 144-152.

Sousa, G.G., Lacerda, C.F., Cavalcante, L.F., Guimarães, F.V.A., Bezerra, M.E.J., Silva, G.L. (2010). Nutrição mineral e extração de nutrientes de planta de milho irrigada com água salina. Revista Brasileira de Engenharia Agrícola e Ambiental, 14(11), 1143-1151. https://doi.org/10.1590/S1415-43662010001100003.

Sousa, G.G., Rodrigues, V.S., Soares, S.C., Damasceno, I.N., Fiusa, J.N., Saraiva, S.E.L. (2018a). Irrigation with saline water in soybean (Glycine $\max$ (L.) Merr.) in a soil with bovine biofertilizer. Revista Brasileira de Engenharia Agrícola e Ambiental, 22(9), 604-609. https://doi.org/10.1590/1807-1929/agriambi.v22n9p604-609.

Sousa, G.G., Sousa, C.H.C., Souza, M.V.P., Freire, M.H.C., Silva, G.L. (2018b). Trocas gasosas na cultura da fava irrigada com águas salinas. Irriga, 1(2), 19-23. https://doi.org/10.15809/irriga.2018v1n2p19-23.

Sousa, V.F.O. Comportamento vegetativo, fisiológico e produtivo na cultura do meloeiro sob salinidade. (2017). Ano de obtenção: 2017. 64 f. Dissertação (Mestrado em Horticultura Tropical) - Universidade Federal de Campina Grande.

Souza, R.P., Machado, E.C., Silveira, J.A.G., Ribeiro, R.V. (2011). Fotossíntese e acúmulo de solutos em feijoeiro caupi submetido à salinidade. Pesquisa Agropecuária Brasileira, 46(6), 586-592. http://dx.doi.org/10.1590/S0100-204X2011000600003.

Taiz, L., Zeiger, E., Moller, I.M., Murphy, A. (2017). Fisiologia e desenvolvimento vegetal. 6.ed. Porto Alegre: ARTEMED.

Teixeira, P.C., Donagemma, G.K., Fontana, A., Teixeira, W.G. (2017). Manual de métodos de análise de solo. 3.ed. Brasília: Embrapa Informação Tecnológica. 